\title{
O gênero Olpidiopsis (Oomycota) no Nordeste do Brasil
}

\author{
The genus Olpidiopsis (Oomycota) in northeastern Brazil
}

\author{
José de Ribamar de Sousa Rocha ${ }^{1,2,3}$, Joseane Lustosa Machado ${ }^{1}$, Janete Barros da Silva ${ }^{1}$, \\ Osiel César da Trindade Júnior ${ }^{1}$, Leilane de Abreu Santos ${ }^{2}$, Edilson Páscoa Rodrigues ${ }^{2}$ \\ \& Áurea Aguiar Cronemberger ${ }^{2}$
}

\begin{abstract}
Resumo
Estudos sobre a diversidade de oomicetos foram realizados de 1998 a 2016, na Bahia, Maranhão e Piauí, e parasitas biotróficos holocárpicos zoospóricos de quitrídias, glomeromicetos e oomicetos foram identificados como Olpidiopsis achlyae, O. aphanomycis, O. fusiformis, O. karlingae, Olpidiopsis sp1 e Olpidiopsis sp2. A ocorrência de O. karlingae é novo relato para a América do Sul e de O. aphanomycis, para o Brasil. Os táxons encontrados foram descritos, ilustrados e comentados. A diversidade de termos da literatura especializada para identificação das estruturas morfológicas de Olpidiopsis foi padronizada. São propostas as sinonímias de O. braziliensis (= Pseudolpidium achlyae) com O. fusiformis e de Cornumyces karlingae com O. karlingae.
\end{abstract} Palavras-chave: biodiversidade, distribuição geográfica, organismos zoospóricos heterotróficos, parasitas.

\begin{abstract}
Studies on the diversity of oomycetes were carried out from 1998 to 2016, in the states of Bahia, Maranhão and Piauí, and biotrophic holocarpic zoosporic parasites of chitrids, glomeromycetes and oomycetes were identified as Olpidiopsis achlyae, O. aphanomycis, O. fusiformis, O. karlingae, Olpidiopsis sp 1 and Olpidiopsis sp2. The occurrence of $O$. karlingae is a new report for South America, and O. aphanomycis, for Brazil. The taxa found were described, illustrated, and commented. The diversity of terms of the specialized literature for identification of morphological structures of Olpidiopsis was standardized. Are proposed synonyms of O. braziliensis (= Pseudolpidium achlyae) with $O$. fusiformis and Cornumyces karlingae with O. karlingae.
\end{abstract} Key words: biodiversity, geographic distribution, heterotrophic zoosporic organisms, parasites.

\section{Introdução}

O termo geral "fungos" abrange um grupo bastante diverso que inclui os organismos tradicionalmente estudados pelos micologistas, tais como os fungos verdadeiros, do reino Eumycota; bem como outros grupos de organismos relacionados a fungos, como os Plasmodiophorales, Rozellopsidales, Lagenismatales, Ectrogellaceae e Olpidiopsidales. Estes organismos similares a fungos são flagelados e, juntamente com Peronosporomycetina, Blastocladiomycota, Neocallimastigomycota e Chytridiomycota, são conhecidos como "fungos zoospóricos", compartilham estratégias tróficas similares, como saprofitismo, parasitismo e associações simbióticas e podem ocorrer no mesmo ecossistema. (Dick 1997, 2001a; Sime-Ngando 2012).

Entre os organismos zoospóricos análogos aos fungos (estraminipilas osmotróficos), os oomicetos (Oomycota) representam o maior grupo, com mais de mil espécies e as mais conhecidas são aquelas espécies parasitas de plantas ou de animais, inclusive, humanos (Beakes et al. 2014; Kwak et al. 2017; Sekimoto et al. 2008b).

Os parasitas têm forte influência nos processos ecológicos como a dinâmica da população, sucessão de espécies, competição por recursos, diversificação de espécies e fluxo de energia e de genes (Hudson et al. 2006; Shearer et al. 2007, Sime-Ngando 2012). Parasitas em ambientes

\footnotetext{
${ }^{1}$ Universidade Federal do Piauí, Campus Min. Petrônio Portella, PRODEMA, Núcleo de Pesquisa do Trópico Ecotonal do Nordeste - TROPEN, Av. Universitária 1310, Ininga, 64049-550, Teresina, PI, Brasil.

${ }^{2}$ Universidade Federal do Piauí, Campus Min. Petrônio Portella, Centro de Ciências da Natureza, Depto. Biologia, Av. Universitária s/n, Ininga, 64049-550, Teresina, PI, Brasil.

${ }^{3}$ Autor para correspondência: ribamar10@hotmail.com
} 
aquáticos são menos estudados que os de ambientes terrestres (Kuris et al. 2008), apesar de ocorrerem praticamente em todos os ambientes (Laffety et al. 2006, 2008). Olpidiopsis é um gênero constituído por parasitas biotróficos obrigatórios (Dick 2001b) e várias espécies são agentes de grandes perdas econômicas em culturas comerciais de algas marinhas cultivadas (Bangia, Porphyra, Pyropia) na Coreia e no Japão (Kim et al. 2014; Klochkova et al. 2016; Kwak et al. 2017; Sekimoto et al. 2008a).

O gênero Olpidiopsis, estabelecido por Cornu (1872), é composto por organismos holocárpicos e não septados, endobióticos. Estas espécies, inicialmente caracterizadas como parasitas de Saprolegniales e de espécies de Pythium, comumente causam severa hipertrofia que resulta na expansão da hifa do hospedeiro e pode variar grandemente na forma e tamanho (Karling, 1942; Sparrow 1960). Historicamente, Olpidiopsis teve posições taxonômicas diversas. A classificação para os oomicetos apresentada por Sparrow (1960), a mais utilizada na última metade do século 20 (Beakes et al. 2014), divide esses organismos em quatro ordens: Saprolegniales, Peronosporales, Lagenidiales e Leptomitales; e Olpidiopsis está incluido na família Olpidiopsidaceae, da ordem Lagenidiales.

Dick (2001a) propôs uma revisão taxonômica de oomicetos com base na reavaliação de informações sobre características morfológicas. A classe Peronosporomycetes tem a ordem Olpidiopsidales posicionada em incertae sedis, e é constituída por uma única família, Olpidiopsidaceae; com três gêneros, Olpidiopsis, Pleocystidium e Gracea. Em trabalho subsequente, Dick (2001b) manteve a mesma hierarquia taxonômica até o nível de ordem, porém, Olpidiopsidales é subdividida em duas famílias, Sirolpidiaceae e Olpidiopsidaceae. Esta última família é composta por dois gêneros, Pleocystidium e Olpidiopsis.

Inicialmente, foi pressuposto que a inabilidade de infecção de uma dada espécie de Olpidiopsis a um hospedeiro de outra espécie de Olpidiopsis seria uma indicação de diferenças fisiológicas de valor taxonômico na diagnose das espécies parasitas (Whiffen 1942). Em estudo de suscetibilidade de hospedeiros, Shanor (1940) observou que Achlya proliferoides é muito suscetível a $O$. varians, mas é imune a $O$. fusiformis. Por outro lado, Achlya klebsiana é suscetível a $O$. fusiformis e não a $O$. varians. Esta seletividade de hospedeiros foi entendida como evidentes diferenças fisiológicas que podem existir dentro de grupos os quais espécies mostram relações mofológicas muito próximas.
Com base nos hospedeiros, as espécies do gênero Olpidiopsis foram distribuídas por Dick (2001b) em três gêneros distintos. Em Olpidiopsis Cornu permaneceram as espécies de hospedeiros terrestres e de água doce; as espécies marinhas parasitas de algas vermelhas foram realocadas em Potisma H. E. Petersen; e aquelas espécies marinhas parasitas de algas verdes foram colocadas em Sirolpidium H. E. Petersen.

Considerando que os oomicetos não formam um clado monofilético bem sustentado estatisticamente e com base em sequência de dados moleculares, foi proposta uma nova revisão taxonômica para os oomicetos por Beakes et al. (2014). Nesta revisão, a ordem Olpidiopsidales s. lat. está posicionada em classe incertae sedis e reune três famílias, Pontismataceae, Sirolpidiaceae e Olpidiaceae s. lat. Esta última família é constituída por um único gênero, Olpidiopsis s. lat., o qual é considerado monofilético e carece de revisão taxonômica (Beakes et al. 2014).

No Brasil, 196 espécies de oomicetos foram relatadas, representando apenas $20 \%$ dos registros mundiais, o que representa uma baixa percentagem considerando que o país tem megadiversidade e dimensões continentais (Maia et al. 2015), evidenciando a necessidade de mais estudos para conhecimento da diversidade desses organismos. Deste total, cinco espécies pertencem a Olpidiopsis: $O$. achlyae, ocorrendo em Minas Gerais, Piauí e São Paulo; O. brasiliensis e O. fusiformis, ambas relatadas no Piauí e em São Paulo; O. saprolegniae var. saprolegniae, ocorrendo em Minas Gerais e São Paulo e O. varians, ocorrendo em São Paulo (Milanez et al. 2007; Steciow et al. 2012). $\mathrm{Na}$ América do Sul, além do Brasil, apenas a Argentina apresenta registros de Olpidiopsis, com seis espécies: $O$. achlyae, $O$. aphonomycis, $O$. saprolegniae, $O$. pythii, $O$. varians e $O$. vexans (Marano et al. 2012; Steciow et al. 2012).

Este artigo relata a distribuição geográfica no Nordeste do Brasil de seis táxons de Olpidiopsis, os quais são decritos e comentados; e propõe novas sinonímias no gênero.

\section{Material e Métodos}

Sete estudos foram desenvolvidos em três estados do Nordeste brasileiro, entre 1988 e 2016 (Tab. 1). Na Bahia, os estudos foram realizados em dois locais, nos municípios de Senhor do Bonfim, em Serra da Maravilha (10²3'59,5'S $\left.40^{\circ} 10^{\prime} 31,3^{\prime \prime} \mathrm{W}\right)$ e Pilão Arcado, em Morro do

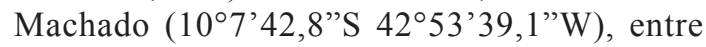


Tabela 1 - Locais e períodos de sete estudos de diversidade de oomicetos (Oomycota) com relato de espécies de Olpidiopsis realizados em três estados brasileiros, entre 1988 e 2016.

Table 1 - Sites and periods of seven studies of oomycete diversity (Oomycota) with reports of Olpidiopsis species carried out in three Brazilian states, between 1988 and 2016.

\begin{tabular}{|c|c|c|c|c|}
\hline Estado & Município & Local de estudo & Coordenadas & Período \\
\hline \multirow{2}{*}{ Bahia } & Pilão Arcado & Morro do Machado & $\begin{array}{l}10^{\circ} 7,0^{\prime} 42,8^{\prime \prime} \mathrm{S} \\
42^{\circ} 53^{\prime} 39,1^{\prime \prime} \mathrm{W}\end{array}$ & $2007-08$ \\
\hline & Senhor do Bonfim & Serra da Maravilha & $\begin{array}{l}10^{\circ} 23^{\prime} 59,5^{\prime \prime} \mathrm{S} \\
40^{\circ} 10^{\prime} 31,3^{\prime \prime} \mathrm{W}\end{array}$ & $2007-08$ \\
\hline Maranhão & Timon & Pq. Nat. Municipal Lagoa Sambico & $\begin{array}{l}49^{\circ} 12^{\prime} 24,4^{\prime \prime} \mathrm{S} \\
42^{\circ} 16^{\prime} 29,0^{\prime \prime} \mathrm{W}\end{array}$ & $2014-15$ \\
\hline \multirow{4}{*}{ Piauí } & Pedro II & Açude Joana & $\begin{array}{l}04^{\circ} 25^{\prime} 56,0 ” \mathrm{~S} \\
41^{\circ} 28^{\prime} 09^{\prime \prime} \mathrm{W}\end{array}$ & $2015-16$ \\
\hline & Piracuruca & Pq. Nacional de Sete Cidades & $\begin{array}{l}04^{\circ} 05^{\prime} 5,97^{\prime \prime} \mathrm{S} \\
41^{\circ} 30^{\prime} 40,0^{\prime \prime} \mathrm{W}\end{array}$ & 1998-2000 \\
\hline & \multirow{2}{*}{ Teresina } & Lagoa Piçarreira do Cabrinha & $\begin{array}{l}50^{\circ} 64,00^{\prime} 9,9^{\prime \prime} \mathrm{S} \\
42^{\circ} 83 ' 40,7^{\prime \prime} \mathrm{W}\end{array}$ & $2011-12$ \\
\hline & & Pq. Ambiental Encontro dos Rios & $\begin{array}{l}50^{\circ} 50,0^{\prime} 7,1 \text { '”S } \\
42^{\circ} 83^{\prime} 40,2^{\prime \prime} \mathrm{W}\end{array}$ & $2013-14$ \\
\hline
\end{tabular}

maio de 2007 e fevereiro de 2008. No Maranhão, o estudo foi desenvolvido no município de Timon, no Parque Natural Municipal Lagoa do Sambico $\left(49^{\circ} 12^{\prime} 24,4^{\prime \prime} \mathrm{S}\right.$ e $\left.42^{\circ} 16^{\prime} 29,0^{\prime \prime} \mathrm{W}\right)$, de junho de 2014 a junho de 2015. No Piauí, os estudos foram realizados em quatro locais. O primeiro foi o Parque Nacional de Sete Cidades (04 $05^{\circ} 5,97^{\prime}$ 'S

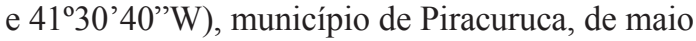
de 1998 a fevereiro de 2000. O segundo e terceiro locais de estudos foram no município de Teresina, na lagoa Piçarreira do Cabrinha (5064'9,97'S e 42 83 '40,73”'W), de março de 2011 a junho de 2012; e no Parque Ambiental Encontro dos Rios, situado nas confluências dos rios Parnaíba e Poti (50'50'7,11'S e 42 $\left.83^{\circ} 40,27^{\prime \prime} \mathrm{W}\right)$, de julho 2013 a janeiro de 2014. O quarto local de estudo foi no município de Pedro II, no Açude Joana $\left(4^{\circ} 25^{\prime} 56^{\prime}\right.$ ”S e $41^{\circ} 28^{\prime} 09^{\prime \prime} \mathrm{W}$ ), de agosto de 2015 a agosto de 2016.

Para estudo de oomicetos, amostras de água superficiais foram coletadas e depositadas em frascos de vidro $(100 \mathrm{~mL})$, juntamente com detritos vegetais e animais. Amostras de solo $(200 \mathrm{~g})$ foram coletadas das margens em saco de polietileno. Após a coleta, as amostras de água e de solo foram rotuladas com informações dos pontos de coleta e transportadas para processamento no Laboratório de Micologia, da Universidade Federal do Piauí (UFPI). Os oomicetos foram isolados das amostras de água e de solo, com a adaptação de técnicas de iscagem múltipla e de manutenção de cultura (Shanor 1939; 1940; Fuller \& Jaworski 1987; Milanez 1989). De cada amostra de água juntamente com os detritos orgânicos vegetais e animais, foram transferidas alíquotas $(30 \mathrm{~mL})$ para placas de Petri $(100 \times 20 \mathrm{~mm})$ rotuladas com informações do ponto de coleta. Das amostras de solo, foram transferidas alíquotas $(20 \mathrm{~g})$ para placas de petri $(100 \times 20 \mathrm{~mm})$ rotuladas com informações do ponto de coleta, dissolvidas em $30 \mathrm{~mL}$ de água destilada esterilizada e decantadas por $30 \mathrm{~min}$. Em todas as placas de Petri preparadas com amostras de água e amostras de solo, foram adicionadadas iscas múltiplas constituídas por substratos celulósicos (sementes de Sorghum sp., palha de milho, celofane e epiderme de cebola), queratinosos (ecdise de cobra, escama de peixe e cabelo) e quitinosos (asa de térmite e exoesqueleto de camarão). Após incubação por sete dias, em temperatura ambiente $\left(30-32^{\circ} \mathrm{C}\right)$, lâminas preparadas com água e detritos orgânicos coletados e com os substratos celulósicos, queratinosos e quitinosos foram examinadas ao microscópio óptico (Olympus BX41, Tokyo, Japan) para observação de colonização por oomicetos e verificação de parasitismo. A identificação taxonômica dos parasitas e dos hospedeiros foi realizada consultando literatura especializada (Karling 1942; Sparrow 1960; Johnson et al. 2005, e descrições originais de táxons). Após identificação, as espécies foram descritas, ilustradas em câmara clara acoplada a microscópio óptico (Olympus 
BX41, Tokyo, Japan) e fotografadas (Nikon Coolpix-S4100). As descrições do desenvolvimento dos patógenos foram realizadas com observações aleatórias em sucessivas montagens de lâminas com material de culturas do hospedeiro onde ocorria parasitismo por oomicetos. A classificação taxonômica adotada foi a proposta por Beakes et al. (2014) e os nomes científicos e a abreviação dos autores seguiu Species Fungorum (2017). Lâminas semipermanentes foram preparadas com azul de algodão, lactofenol e espécimes selecionados e depositadas na coleção de fungos zoospóricos e organismos similares a fungos zoospóricos, denominada "Collection zoosporic fungi and organisms similar to zoosporic fungi of Brazil", sigla ZFBR, do laboratório de Micologia, UFPI. O acervo documental de cada espécie de parasita é constituído por lâminas semipermanentes, fotografias, ilustrações em câmara-clara, descrições morfofisiológicas e culturas, foi tombado na coleção ZFBR e recebeu um respectivo número de acesso. Como os parasitas são biotróficos, não é possível a cultura do desses organismos sem o hospedeiro. A manutenção das culturas do parasita em estoque foi realizada com sucessivas culturas do hospedeiro não parasitado em novos substratos e posterior inoculação com a transferência dos parasitas (em hospedeiros) para estas culturas. Este procedimento torna as infecções mais vigorosas (Shanor 1940). As culturas do parasita no hospedeiro foram mantidas em estufa com demanda de oxigênio (BOD), a $12{ }^{\circ} \mathrm{C}$. A vida útil da cultura estoque é por tempo indeterminado, dependendo da viabilidade dos oósporos preservados dos parasitas e de seus hospedeiros.

\section{Resultados e Discussão}

Em estudos de diversidade de oomicetos realizados no nordeste do Brasil, parasitas de diversos hospedeiros (quitridiomicetos, glomeromicetos e de outros oomicetos), foram identificados no gênero Olpidiopsis e, segundo a classificação de Beakes et al. (2014), pertecem ao reino Straminipila, filo Oomycota, classe incertae sedis, ordem Olpidiopsidales s. lat., família Olpidiopsidaceae s. lat., gênero Olpisiopsis s. lat.

As espécies relatadas são $O$. achlyae McLarty, O. aphanomycis Cornu, O. fusiformis Cornu, $O$. karlingae Karling, Olpidiopsis sp1 e Olpidiopsis sp2. A ocorrência de $O$. karlingae é novo relato para a América do Sul e O. aphanomicys, para o Brasil (Tab. 2).

Historicamente, estruturas morfológicas receberam denominações variadas nas descrições das espécies de Olpidiopsis entre os diversos estudiosos do gênero, como Shanor $(1939,1940)$, Karling (1942), Sparrow (1960), Dick (2001a, 2001b), Sekimoto et al. (2008b, 2009), Klochkova et al. (2016), Kwak et al. (2017), dentre outros. Neste trabalho, termos utilizados para denominação de uma mesma estrutura morfológica foram uniformizados objetivando padronizar as descrições. O "talo" é

Tabela 2 - Distribuição geográfica em três estados brasileiros de espécies de Olpidiopsis e seus hospedeiros. Table 2 - Geographical distribution in three Brazilian states of Olpidiopsis species and their hosts.

\begin{tabular}{|c|c|c|c|c|}
\hline Estado & Município & Local de estudo & Espécie & Hospedeiro \\
\hline \multirow{3}{*}{ Bahia } & \multirow[t]{2}{*}{ Pilão Arcado } & \multirow[t]{2}{*}{ Morro do Machado } & Olpidiopsis sp1 & $\begin{array}{l}\text { Glomeromycota } \\
\text { (Micorriza inespecífica) }\end{array}$ \\
\hline & & & O. aphanomycis* & Aphanomyces keratinophilus \\
\hline & Senhor do Bonfim & Serra da Maravilha & O. karlingae $* *$ & Rhizophlyctis rosea \\
\hline \multirow[t]{2}{*}{ Maranhão } & Timon & Pq. Nat. Municipal Lagoa Sambico & O. aphanomycis* & Aphanomyces keratinophilus \\
\hline & Pedro II & Açude Joana & Olpidiopsis sp2 & $\begin{array}{l}\text { Glomeromycota } \\
\text { (Micorriza inespecífica) }\end{array}$ \\
\hline \multirow[t]{3}{*}{ Piauí } & Piracuruca & Pq. Nacional de Sete Cidades & $\begin{array}{l}\text { O. fusiformis } \\
\text { O. achlyae }\end{array}$ & $\begin{array}{l}\text { Achlya diffusa } \\
\text { Achlya diffusa e Achlya orion }\end{array}$ \\
\hline & \multirow[t]{2}{*}{ Teresina } & Lagoa Piçarreira do Cabrinha & $\begin{array}{l}\text { O. aphanomycis* } \\
\text { O. achlyae }\end{array}$ & $\begin{array}{l}\text { Aphanomyces keratinophilus } \\
\text { Achlya proliferoides }\end{array}$ \\
\hline & & Pq. Ambiental Encontro dos Rios & O. achlyae & Achlya proliferoides \\
\hline
\end{tabular}

* Primeiro relato para o Brasil. **Primeiro relato para a América do Sul. 
designado micélio (significando uma célula ou o conjunto de células vegetativas de Olpidiopsis que se diferenciam em estruturas reprodutivas sexuais e assexuais); os "talos contribuintes" são designados gametângios, onde o "talo receptivo" é designado oogônio e o "talo contribuinte", "gametângio doador", "célula masculina" ou "célula companheira" é designado anterídio; e o "esporo de resistência", que consiste no conjunto do oogônio com o oósporo plerótico, é designado apenas oósporo. Em algumas descrições de espécies apenas as características do oósporo são referidas, como a ornamentação, forma e tamanho; considerando que em Olpidiopsis os oósporos são pleróticos, estas características são implícitas ao oogônio.

As culturas com a indução de infecção das espécies de Olpidiopsis obtiveram pouco ou, às vezes, nenhum resultado positivo. Na manutenção das culturas hospedeiro-parasita em temperatura ambiente, a $30-32{ }^{\circ} \mathrm{C}$, e a fase de desenvolvimento do hospedeiro (antes ou depois da formação de estruturas reprodutivas) no momento de infecção pode ter limitado o sucesso de Olpidiopsis no processo de parasitismo. Segundo Slifkin (1961), acima de 30 ${ }^{\circ} \mathrm{C}$ Olpiopsis incrassata perdia infectividade e o processo de infecção não ocorria após o início de formação de zoosporângio e oogônio.

Olpidiopsis achlyae McLarty Bulletin of the Torrey Botanical Club. 68: 62. $1941 . \quad$ Fig. 1a-d Olpidiopsis fusiformis f. achlyae (McLarty) Ceip Olpidiopsis fusiformis f. fusiformis Cornu

Micélio endobiótico, holocárpico, geralmente causando hipertrofia nas hifas do hospedeiro. Zoosporângio um a vários em cada hipertrofia de hifa; hialino ou cinza com aspecto granular; muito variável em tamanho e forma, esférico, 20-380 $\mu \mathrm{m}$ diâm., oval, fusiforme; liso; liberação de zoósporos por um tubo de liberação. Zoósporos não observados. Oogônio com oósporo plerótico. Oósporo partenogenético ou sexual; marronclaro ou hialino; oval, esférico, 30-80 $\mu \mathrm{m}$ diâm., endosporo delgado, exosporo espesso, 1,5-2 $\mu \mathrm{m}$, coberto com fibrilas finas, $4-8 \mu \mathrm{m}$ comprimento; conteúdo granular com vários ou apenas um grande glóbulo refrativo. Anterídio quando presente 1(-3) por oogônio; parede delgada; hialino; liso; oval ou esférico. Germinação de oósporo não observada.

Material examinado: PIAUÍ: Teresina, Parque Ambiental Encontro dos Rios, 25.IX.2013. L.A.Santos. ZFBR 163.

Material suplementar: BRASIL. PIAUII: Teresina, Lagoa Piçarreira do Cabrinha. 23.V. 2011. O.C.TrindadeJúnior. ZFBR 164.
Distribuição geográfica no Brasil: MINAS GERAIS: Ingaí (Milanez et al. 2007). PIAUÍ: Parque Nacional de Sete Cidades (Rocha 2002). SÃO PAULO: Cubatão (Pires-Zottarelli 1999), São Paulo (Rogers et al. 1970).

$\mathrm{Na}$ descrição original de $O$. achlyae o hospedeiro relatado foi Achlya flagellata (McLarty 1941). Neste estudo, no Parque Ambiental Encontro dos Rios e na Lagoa Piçarreira do Cabrinha, em ambos os locais, o parasita teve como hospedeiro A. proliferoides Coker. Na primeira citação para o Piauí, o hospedeiro de $O$. achlyae foi $A$. diffusa Harvey ex Johnson e A. orion Coker \& Couch (Rocha 2002). Em São Paulo, os hospedeiros relatados foram Achlya spp., Dictyuchus spp. (PiresZottarelli, 1999) e A. flagellata (Rogers et al. 1970).

O material examinado concorda com a descrição original. No processo de infecção, $O$. achlyae provocou dilatação de hifas em $A$. proliferoides (Fig.1a-e), com a formação de zoosporângios de formas e tamanhos variados (Fig. 1a), apresentando conteúdo granular (Fig. 1a-b). Os oósporos formaram fibrilas finas na parede externa (Fig. 1c-e) e podiam apresentar coloração marron-clara (Fig. 1d) ou eram hialinos, com anterídio esférico (Fig. 1c). Em uma mesma dilatação poderiam ser formados zoosporângios e oósporos (Fig. 1e).

Olpidiopsis achlyae tem estruturas muito variáveis e pode produzir oósporos com exosporo que podem ser característicos de várias espécies do gênero (Karling 1942). Sparrow (1960) concorda com a possibilidade sugerida por McLarty (1941) e Karling (1942) de que esta espécie pode ser relacionada a $O$. fusiformis. Segundo Karling (1942), é provável que $O$. achlyae, $O$. varians, $O$. index e $O$. spinosa sejam variedades biológicas de $O$. fusiformis, as quais seriam limitadas a hospedeiros particulares, e que todas as espécies de Olpidiopsis parasitas de Achlya sejam variedades de uma única espécie.

Olpidiopsis aphanomycis Cornu, Annls de Sciences Naturelles, Botanique, série 5(15): 148. 1872.

Fig. 2a-f

Pseudolpidium aphanomyces (Cornu) A. Fisch. Olpidiopsis luxurians Barret

Micélio endobiótico, holocárpico, geralmente causando hipertrofia nas hifas do hospedeiro. Zoosporângio um a vários em cada hipertrofia de hifa; hialino ou cinza, com aspecto granular; esférico, 15-45 $\mu \mathrm{m}$ diâm., oval, fusiforme; liso; liberação de zoósporos por um tubo de liberação. Zoósporos 

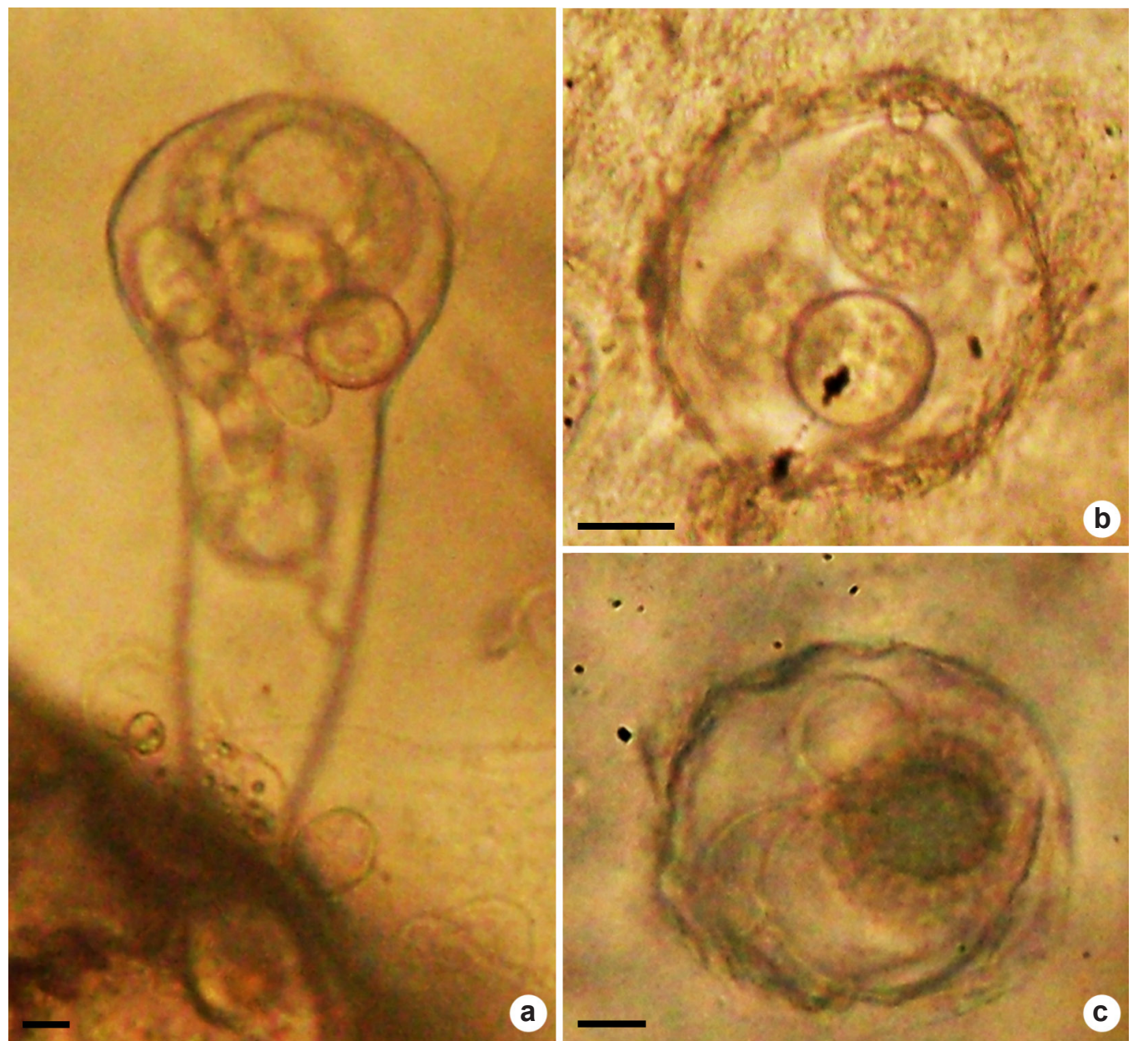

a
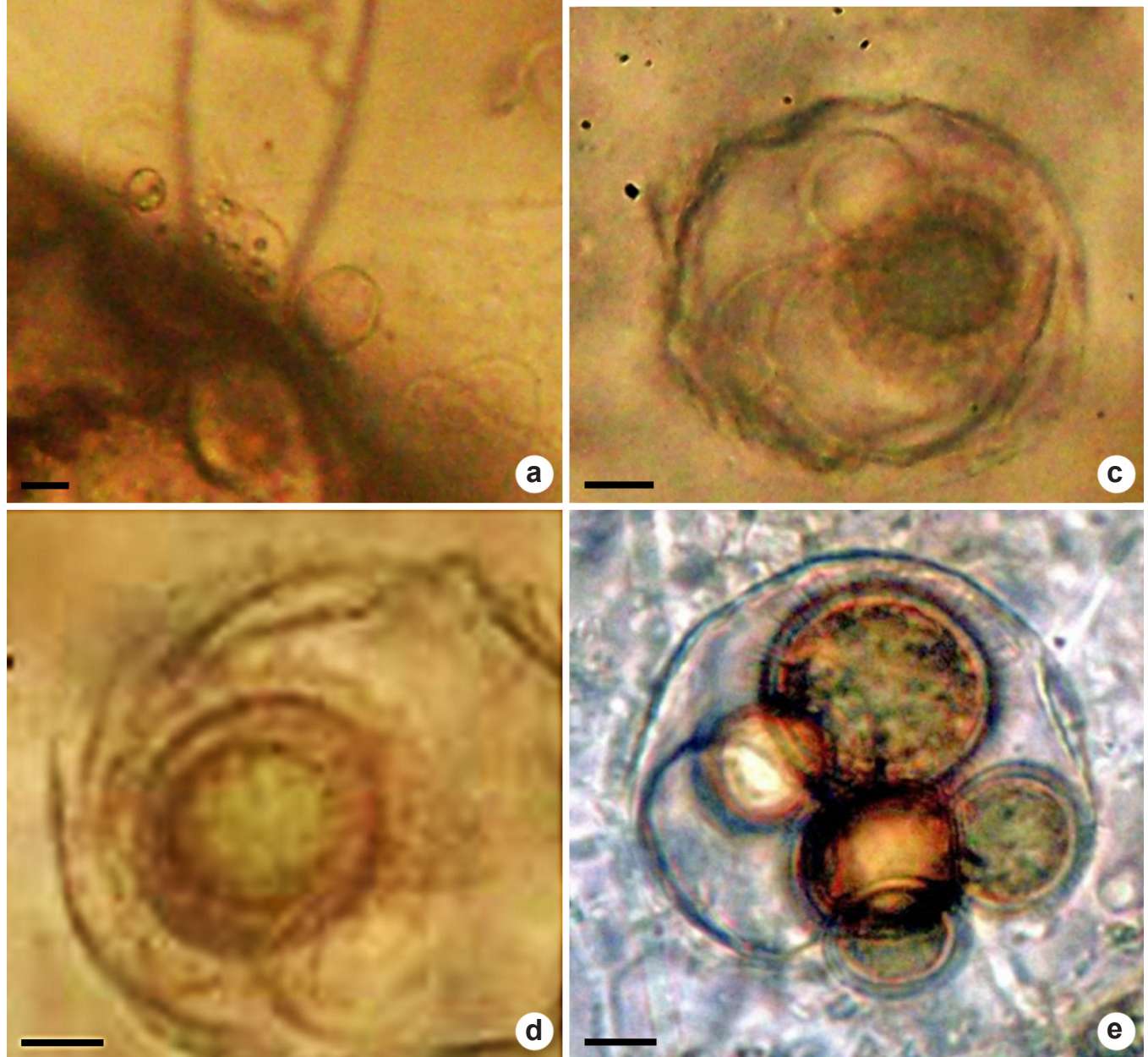

Figura 1 - Estruturas de Olpidiopsis achlyae produzidas em dilatação de hifas de Achlya proliferoides - a. zoosporângios de formas e tamanhos variados; b. zoosporângios esféricos de conteúdo granular; c. oósporo coberto por fibrilas finas e com um anterídio vazio; d. oósporo marron-claro; e. oósporos cobertos por fibrilas finas e um zoosporângio ovóide vazio. Barras $=45 \mu \mathrm{m}$.

Figure 1 - Structures of Olpidiopsis achlyae produced in dilation of hyphae of Achlya proliferoides - a. zoosporangia of varied shapes and sizes; $b$. spherical zoosporangia of granular content; c. oospore covered by fine fibrils and with an empty antheridium; d. oospore light brown; e. oospores covered by fine fibrils and empty ovoid zoosporangia. Bars $=45 \mu \mathrm{m}$ 

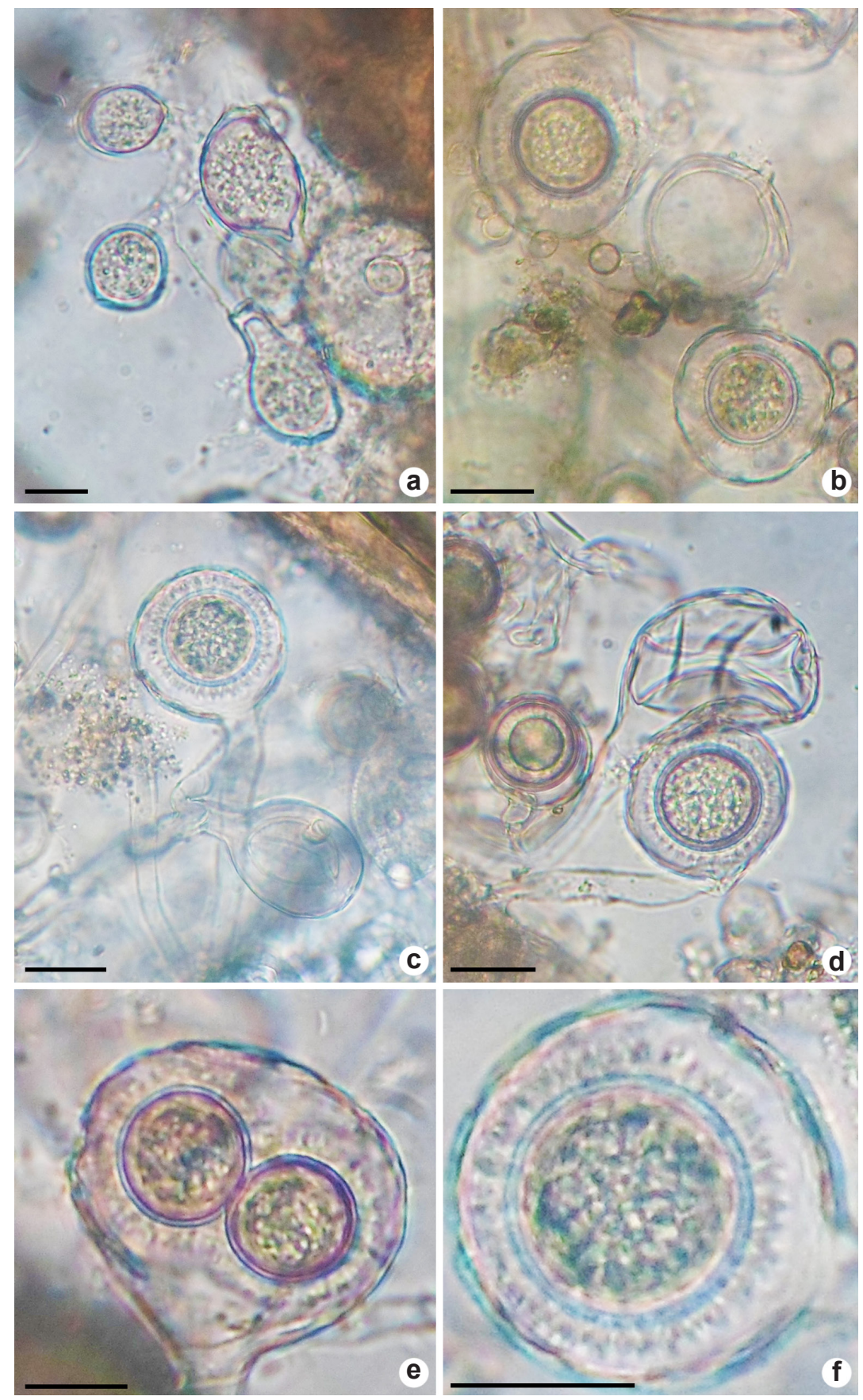

Figura 2 - Estruturas de Olpidiopsis aphanomycis produzidas em dilatação de hifas de Aphanomyces keratinophilus - a. zoosporângios de tamanhos e formas diversas com conteúdo granular; b. zoosporângio esférico vazio com curto tubo de liberação e dois oósporos cobertos por espinhos com conteúdo granular; c. oósporo coberto por espinhos com conteúdo granular e um zoosporângio vazio com curto tubo de liberação; d. oogônio com oósporo do hospedeiro, íntegros. Um zoosporângio vazio. Um oósporo coberto por espinhos com conteúdo granular; e. dois oósporos coberto por espinhos com conteúdo granular e parede espessa, na mesma dilatação de hifa; $\mathrm{f}$. oósporo coberto por espinhos com conteúdo granular e parede espessa. Barras $=45 \mu \mathrm{m}$. Figure 2 - Structures of Olpidiopsis aphanomycis produced in dilation of hyphae of Aphanomyces keratinophilus - a. zoosporangia of various sizes and shapes with granular content; b. empty spherical zoosporangia with short release tube and two oospores covered by spines with granular content; c. oospore covered by spines with granular contents and empty zoosporangium with short release tube; d. oogonium with host oospore, intact. Empty zoosporangium. An oospore covered by spines with granular content; e. two oospores covered by spines with granular content and thick wall, in the same dilation of hypha; f. oospore covered by spines with granular content and thick wall. Bars $=45 \mu \mathrm{m}$. 
6-8 $\mu \mathrm{m}$ diâm. Oogônio com oósporo plerótico. Oósporo partenogenético; hialino; oval, esférico, 13-44 ㅆm diâm.; endosporo delgado, exosporo espesso, 1,5-2 $\mu \mathrm{m}$, coberto com espinhos cônicos, 4-6 $\mu \mathrm{m}$ comprimento; conteúdo granular com um ou mais grandes glóbulos refrativos. Anterídio ausente. Germinação de oósporo não observada.

Material examinado: MARANHÃO: Timon, Parque Natural Municipal Lagoa Sambico, 20.X.2014, J.B Silva; 23.II.2015, J.B Silva; 20.V.2015, J.B Silva. ZFBR 152.

Material suplementar: BRASIL. BAHIA: Pilão Arcado, 23.IX.2007, E.P. Rodrigues ZFBR 165. PIAUÍ: Teresina, Lagoa Piçarreira do Cabrinha, 23.V.2011, O.C.TrindadeJúnior. ZFBR 166.

Distribuição geográfica no Brasil: MARANHÃO: Timon. BAHIA: Pilão Arcado. Estes são os primeiros registros da espécie para o Brasil e extendem a distribuição geográfica de $O$. aphanomycis na América do Sul, onde o único registro do táxon era para Buenos Aires, Argentina (Steciow et al. 2012).

A diversidade de hospedeiros é variada para $O$. aphanomycis, como Aphanomyces laevis (Butler \& Bysby 1931; Staniak 1971), A. cladogamus (Whiffen 1942) e Pythium monospermum (Upadhyay \& Palni 2009). Neste estudo, o hospedeiro relatado foi Aphanomyces keratinophilus em Pilão Arcado, na Bahia; em Timon, no Maranhão; e em Teresina, Piauí.

Os isolados examinados apresentaram estruturas com dimensões compatíveis com a variação observada por Cornu (1872), Karling (1944) e Sparrow (1960). No processo de infecção, o parasita produz células vegetativas globulares dispersas na hifa do hospedeiro, migrando para as extremidades onde são formados os zoosporângios e oogônios do hospedeiro. Subsequentemente, estruturas reprodutivas assexuais do parasita se desenvolvem dentro dos zoosporângios ou oogônios do hospedeiro (Fig. 2a). Os zoosporângios do parasita podem ser solitários ou múltiplos, com parede lisa, hialino ou cinza, com aspecto granular; geralmente esférico, apresentando um tubo de liberação que se extende através da parede do hospedeiro (Fig. 2b-d). O oósporo é hialino; oval, esférico; com parede externa (exosporo) coberta com espinhos cônicos de 2-4 $\mu \mathrm{m}$ de comprimento (Fig. 2b-f); o conteúdo se apresenta granular com um ou mais glóbulos refrativos.

A diagnose original de Cornu (1872) para O. aphanomycis é muito restrita, cita apenas "zoosporângios esféricos, solitários ou em grupos de três ou mais em dilatações terminais ou intercalares na hifa do hospedeiro, com um único tubo de liberação. Zoósporos e oósporos não observados". Posteriormente, Dangeard (1890) atribuiu a este táxon um isolado que apresentava oósporo com espinhos e era parasita de Aphanomyces sp. e de Pythium sp. e não apresentava anterídio. Karling (1942) colocou O. luxurians Barret em sinonímia com O. aphanomycis Cornu, e redefiniu a diagnose do táxon inserindo as características de zoósporos, oósporos e anterídios de O. luxurians. Karling (1942) incluiu também como característica de $O$. aphanomycis zoosporângios com espinhos, além dos lisos, característica não relatada por outros autores e que não consta na diagnose original de O. luxurians. Neste estudo, nenhum zoosporângio com espinhos foi observado, e estes apresentavam um único tubo de liberação; diferente do descrito por Karling (1942), que cita zoosporângio com um a vários tubos de liberação; e de Sparrow (1960), que cita zoosporângios com um ou dois tubos de liberação.

Nenhuma verruga foi observada no oósporo, apenas espinhos (Fig. 2b-f), discordando do que relatam Karling (1942) e Sparrow (1960); e concordando com Barret (1912), que não cita formação de verrugas no oósporo em $O$. luxurians $(=O$. aphanomycis $)$. Os oósporos foram hialinos e nenhum se apresentou marron, como relatado por Karling (1942), e questionado por Sparrow (1960) quando transcreve [... resting spore... (brownish?) wall... p.942]. Nenhum anterídio foi observado neste estudo, diferentemente da redefinição da espécie sensu Karling e sensu Sparrow. Apesar de citar oósporo sem anterídio, o primeiro autor também inclui a ocorrência de um a três por oósporo; e o segundo autor, de apenas um anterídio por oósporo. Sparrow (1960) redefiniu $O$. aphanomycis baseado em suas próprias observações e incluiu a formação de anterídio nas características do táxon; mas, manteve $O$. luxurians um táxon válido, sem entrar em sinonímia com O. aphanomycis, como o fez Karling (1942). Atualmente, a sinonímia proposta por Karling é aceita (Species Fungorum 2016).

Olpidiopsis fusiformis Cornu, Monographie des Saprolegniees: 147. 1872.

Fig. 3a-f

Pseudolpidium achlyae Viégas \& Teixeira sin. nov. Pseudolpidium fusiforme (Cornu) A. Fisch.

Olpidiopsis braziliensis Sparrow sin. nov. Olpidiopsis fusiformis var. oedogonium Sorokin Olpidiopsis fusiformis var. fusiformis Cornu Olpidiopsis minor A. Fisch Olpidiopsis oedogonium (De Wild.) Scherff. 

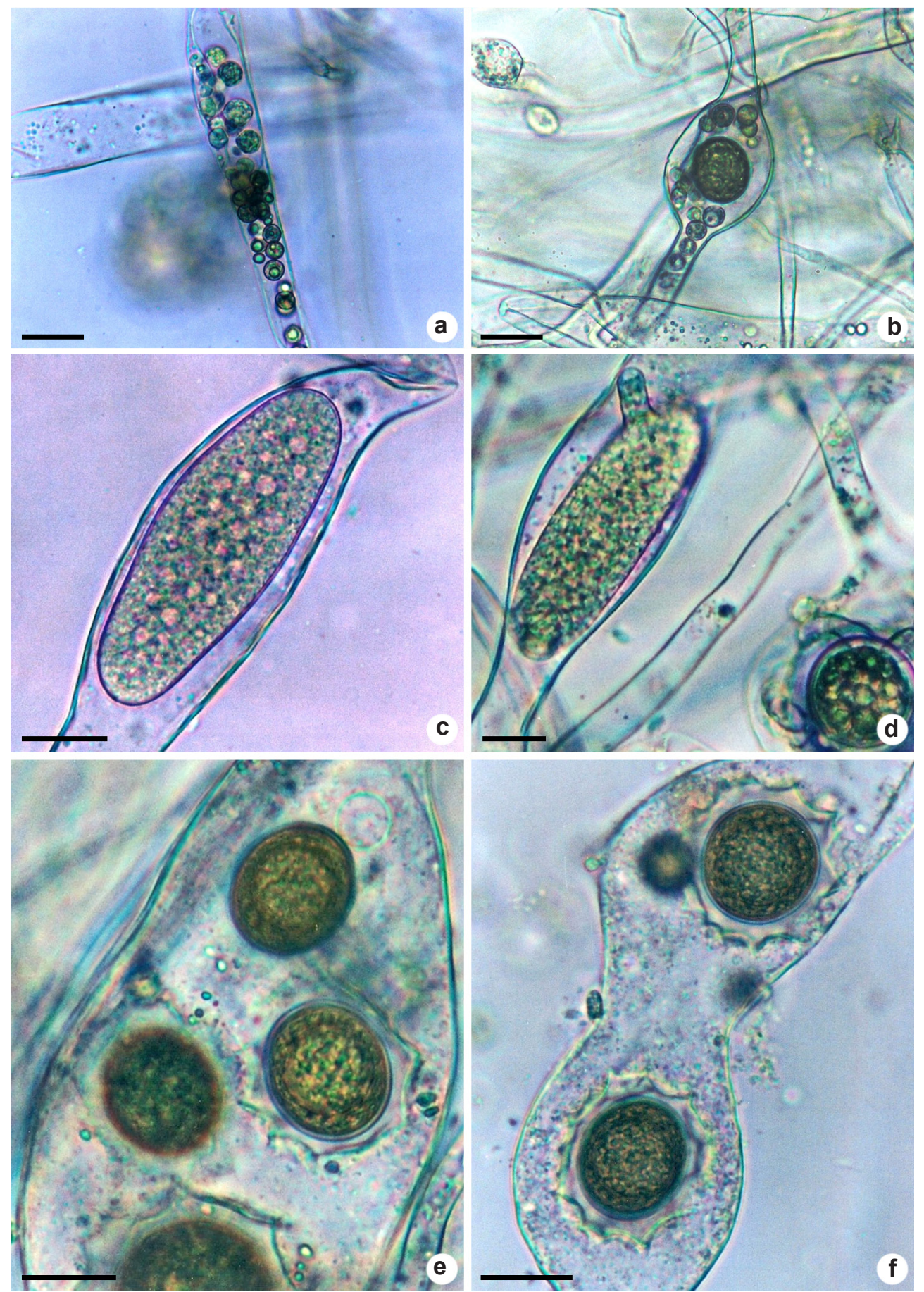

Figura 3 - Estruturas de Olpidiopsis fusiformis produzidas em dilatação de hifas de Achlya orion -a. micélio do parasita com várias células de tamanhos e formas diversas; b. micélio do parasita com diversas células de tamanhos e formas variadas e um oósporo de parede lisa; c. zoosporângio oblongo com conteúdo granular; d. moosporângio com conteúdo granular e tubo de liberação; e. oósporo de parede lisa com um anterídio vazio e os outros oósporos cobertos com espinhos de base larga, em uma mesma dilatação de hifa; f. dois oósporos coberto por espinhos de base larga, com conteúdo granular e parede espessa. Barras $=45 \mu \mathrm{m}$. Figure 3-Structures of Olpidiopsis fusiformis produced in hyphal dilatation of Achlya orion -a. parasite mycelium with several cells of different sizes and shapes; b. parasite mycelium with several cells of varying sizes and shapes and a smooth wall oospore; c. oblong zoosporangium with granular content; d. zoosporangium with granular content and release tube; $\mathrm{e}$. a smooth wall oospore with an empty antheridium and the other oospores covered with broad-based spines, in the same hyphal dilatation; f. two oospores covered by broad-based spines, with granular content and thick wall. Bars $=45 \mu \mathrm{m}$. 
Micélio endobiótico, holocárpico, geralmente causando hipertrofia nas hifas do hospedeiro. Zoosporângio um a vários em cada hipertrofia de hifa; incolor; liso ou coberto por espinhos ou cerdas finas ou espessas; variável em tamanho e forma, usualmente fusiforme, cilíndrico, elipsóide ou alongado, $12-62 \times 30-300 \mu \mathrm{m}$; com $1(-3)$ tubos de liberação que atravessam a parede da hifa hospedeira. Zoósporos hialinos, com numerosos pequenos grânulos refringentes; ovóides, 3-4 $\mu \mathrm{m}$. Oogônio com oósporo plerótico. Oósporo esférico ou elipsóide, $16-55 \times 8-62 \mu \mathrm{m}$; hialino, com um glóbulo refringente; parede espessa, coberta com protuberâncias espinhosas, de base estreita ou larga. Anterídio 1-2 por oogônio; ovais ou esféricos; parede delgada, hialina, lisa. Germinação de oósporo não observada.

Material examinado: BRASIL. PIAUÍ: Parque Nacional de Sete Cidades, 26.XI.1999, J.R.S. Rocha. ZFBR 064. Distribuição geográfica no Brasil: SÃO PAULO: Cubatão (Pires-Zottarelli 1999), São Paulo (Rogers et al. 1970; Milanez et al. 1995).

A espécie foi citada pela primeira vez para o Brasil no estado de São Paulo, parasitando hifas de Achlya bisexualis e Achlya sp. (Rogers et al. 1970). Ocorreu em Achlya flagellata (Khulbe 1979) e em Achlya americana (Upadhyay \& Palni 2009). Neste estudo, O. fusiformis foi observado parasitando hifas de Achlya diffusa.

As estruturas de $O$. fusiformis produzidas em dilatação de hifas de Achlya diffusa foram iniciadas com o micélio do parasita constituído por várias células de tamanhos e formas diversas (Fig. 3a) e, posteriormente, com o amadurecimento das estruturas, houve a produção de oósporo de parede lisa (Fig. 3a,e) e de parede com espinhos de base larga (Fig. 3e-f). As dimensões dos espécimes concordam com Rogers et al. (1970) e Milanez et al. (1995), e são maiores que as citadas por PiresZottarelli (1999), zoosporângio 11-57 $\mu \mathrm{m} \times$ 9-22 $\mu \mathrm{m}$ e oósporos 30-41 um diâm. Existe evidente variação de características do zoosporângio e do oósporo, que divergem grandemente entre os autores. Sparrow (1960) cita oósporo incolor com um anterídio sempre presente; enquanto Karling (1942) cita oósporo castanho-claro com a formação de um a três, ou nenhum anterídio. Estas discordâncias dificultam a delimitação da espécie.

Ocorreu a formação de oósporo de parede lisa, ao lado de oósporos de parede coberta com espinhos (Fig. 3b,e), demonstrando a plasticidade morfológica de O. fusiformis. Considerando este aspecto, O. brasiliensis Sparrow apresenta as suas características morfológicas dentro das possibilidades de variações de $O$. fusiformis, inclusive, oósporos de parede lisa, o principal caráter diagnóstico de $O$. brasiliensis; além de também possuir hospedeiro comum a ambos os táxons. É proposta a colocação de $O$. brasiliensis em sinonímia com $O$. fusiformis. Consequentemente, também é proposta a sinonímia de Pseudolpidium achlyae Viégas \& Teixeira com $O$. fusiformis. Sparrow (1960) transferiu P. achlyae para Olpidiopsis sob o binômio O. brazilienzis Sparrow, posteriormente foi adequado para $O$. brasiliensis, grafado com s, (Species Fungorum 2017). Por apresentar oósporo de parede lisa e um anterídio, foi relacionado a Olpidiopsis saprolegniae, entretanto, os resultados de estudos realizados por Shanor (1940), considerando o critério de especificidade de hospedeiro, demostraram ser $O$. saprolegniae confinada a parasitar apenas Saprolegnia e Isoachlya. Por este motivo, Sparrow (1960) manteve $O$. brasiliensis, que é parasita de Achlya, uma entidade taxonômica distinta.

Anteriormente, estudos com Olpidiopsis demonstraram claramente que o número, a forma e tamanho dos zoosporângios, como também as características dos espinhos e de verrugas nos oósporos são altamente variáveis e de pouco valor diagnóstico em distinguir espécies similares (Shanor 1940; Karling 1942; Srivastava 1975). Entre $O$. varians e O. achlyae, por exemplo, considerando estas características citadas é impossível uma diagnose bem definida e, por esta razão, Karling (1942) considerou provisória a classificação de algumas espécies neste gênero, e observou que as espécies Olpidiopsis parasitas de Saprolegnia poderiam ser reunidas sob uma única denominação, $O$. saprolegniae Cornu.

Olpidiopsis karligae Karling. Mycologia 41(3): 271. $1949 . \quad$ Fig. 4a-d Cornumyces karlingae (J.S. Karling) M.W. Dick sin. nov.

Micélio endobiótico, holocárpico, não causando hipertrofia no hospedeiro. Zoosporângio um a vários; hialino; parede lisa; esférico, 12-110 um diâm., oval, oblongo, piriforme, ligeiramente angular quando pressionado por outros zoosporângios; um tubo de liberação de zoósporos; simples; curto, 6-10 $\mu \mathrm{m}$ x 12-18 $\mu \mathrm{m}$, que atravessa a parede da célula do hospedeiro. Zoósporos com muitos grânulos. Oogônio com oósporo plerótico. Oósporo esférico, $8-25 \mu \mathrm{m}$ diâm., oval, oblongo; com parede lisa; hialina; 

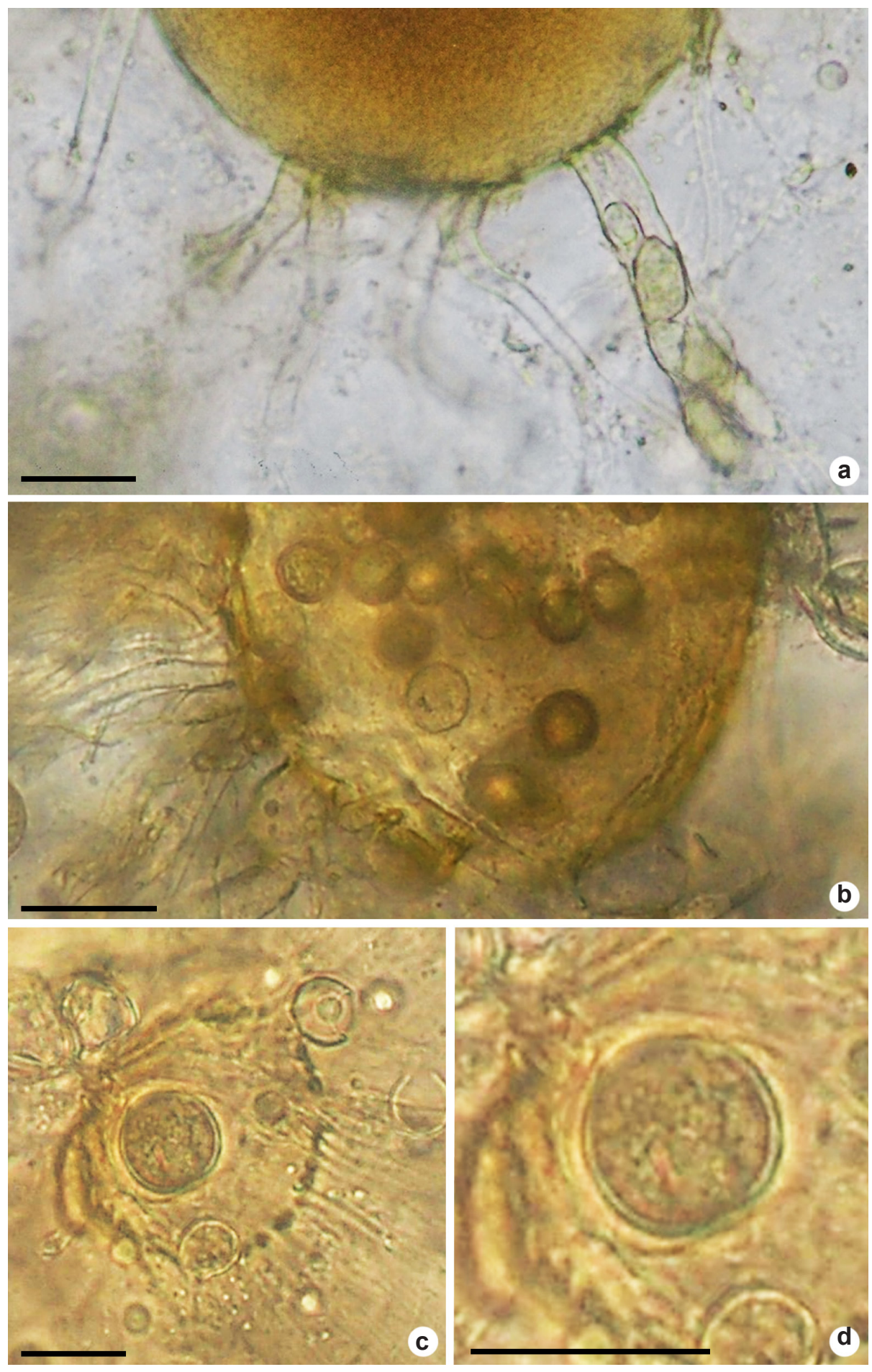

Figura 4 - Estruturas de Olpidiopsis karlingiae produzidas em Rhizophlyctis rosea - a. estágios iniciais de infecção no rizomicélio do hospedeiro; b. diversos oósporos com conteúdo granular e parede espessa no zoosporângio do hospedeiro; c. grande oósporo com conteúdo granular e parede espessa no zoosporângio do hospedeiro; d. oósporo de parede lisa e espessa com conteúdo granular. Barras $=45 \mu \mathrm{m}$.

Figure 4 - Structures of Olpidiopsis karlingiae produced in Rhizophlyctis rosea-a. initial stages of infection in the host rhizomycelium; b. several oospores with granular content and thick wall in the host zoosporangium; c. large oospore with granular content and thick wall in the host's zoosporangium; d. smooth, thick-walled oospores with granular content. Bars $=45 \mu \mathrm{m}$. 
espessa, 1,5-2 $\mu \mathrm{m}$, protoplasma granular com um ou mais vacúolos. Anterídio ausente. Germinação de oósporo não observada.

Material examinado: BRASIL. BAHIA: Senhor do Bonfim. 23.IX.2007, E.P. Rodrigues \& A.A. Cronemberger. ZFBR 167.

Distribuição geográfica no Brasil: BRASIL. BAHIA: Senhor do Bonfim. Este relato é o primeiro registro para a América do Sul.

Originalmente, Olpidiopsis karlingae foi observado parasitando Rhizophlyctis rosea (de Bary \& Woronin) A. Fisch.) (= Karlingia rosea de (Bary \& Woronin) A.E. Johason). O método de infecção e desenvolvimento do parasita dentro do hospedeiro foi fundamentalmente similar a aqueles de outras espécies de Olpidiopsis. Os estágios iniciais de infecção podem ocorrer no rizomicélio (Fig. 4a) ou no zoosporângio do hospedeiro (Fig. 4b-c). Os zoósporos entram em repouso na membrana celular do hospedeiro e transferem o seu conteúdo para o interior do protoplasma do hospedeiro. Os zoósporos tornamse vazios e desaparecem, similarmente ao relatado na descrição original por Karling (1949) (Fig. 4c). Assim como os zoosporângios, os oogônios e oósporos podem ocorrer solitários ou em grande número no hospedeiro (Fig. 4b-c). Houve a formação de grande oósporo de parede lisa e espessa com conteúdo granular (Fig. 4c-d). Em $K$. rosea não ocorreu nenhum evidente enlargamento do hospedeiro, especialmente, no caso de única infecção quando é formado um único oósporo do parasita (Fig. 4a-d).

Olpidiopsis karlingae, segundo Dick (2001b), deve ser removido de Olpidiopsis sensu stricto porque é a única espécie conhecida no gênero a parasitar quitridiomicetos; apresenta o zoósporo relativamente muito grande em relação às outras espécies no gênero, com volume maior que 300 $\mu \mathrm{m}^{3}$; não tem anterídio e não exibe fibrilas externas no oósporo. Entretanto, considera que o parasita não se enquadra completamente em nenhum gênero, mas, poderia ser mais próximo de outro parasita de quitrídia, Petersenia catenophlyctis Sundaram, que fora transferido para Cornumyces sob o binômio C. catenophlyctis (B.M. Sundaram) M.W. Dick, e para o qual $O$. karlingae também fora transferido, sob o binômio C. karlingae (J.S. Karling) M.W. Dick. Neste arranjo taxonômico proposto por Dick (2001b), Cornumyces é um gênero incertae sedis e C. karlingae é uma "espécie duvidosa". Em Cornumyces M.W. Dick há reprodução sexuada por oogônio, entretanto, segundo Dick (2001b), o anterídio não é bem conhecido. Neste estudo, em $O$. karligae não foi observada a formação de anterídio.

No Brasil, segundo Milanez et al. (2007) e Forzza et al. (2010), são citadas duas espécies, Cornumyces destruens (Sparrow) M.W. Dick (= Lagenidium destruens Sparrow) e C. irregulares (Const.) M.W. Dick (= Olpidiopsis irregulares Const.; Petersenia irregulares (Const.) Sparrow).

A série de hospedeiros das espécies de Olpidiopsis naturalmente tende a aumentar e a se diversificar à medida que prosseguem os estudos do gênero (Shanor 1940). Dentro desta pespectiva, a ocorrência de Olpidiopsis em novos hospedeiros, como quitridiomicetos, é aceitável. A não formação de anterídios pode ocorrer em Olpidiopsis, como em $O$. aphanomycis; ou não apresentar fibrilas, como observado em $O$. fusiformis neste estudo, não sendo critérios suficientes para exclusão de O. karlingae de Olpidiopsis, como propôs Dick (2001b).

O esquema de classificação de Dick (2001a, 2001b) não foi baseado em nenhum dado ultraestrutural ou molecular, mas, apenas considerando a série de hospedeiros das espécies, o que é discutível como critério taxonômico, segundo Sekimoto et al. (2008b; 2009), e não foi adotado por estes citados autores na descrição de novas espécies de Olpidiopsis. A falta de conhecimento filogenético torna prematura esta reclassificação de Olpidiopsis em diferentes gêneros, segundo Flechter et al. (2005). Na descrição de novas espécies de Olpidiopsis, Klochkova et al. (2016) também não adotaram a classificação proposta por Dick (2001a, 2001b), por concordarem com as restrições observadas por Sekimoto et al. (2008b; 2009). Concordando com Sekimoto et al. (2008b; 2009), quanto à discutível solidez em adotar a gama de hospedeiros como critério taxonômico para reclassificar as espécies de Olpidiopsis; concordando também com Flechter et al. (2005), que consideram prematura reclassificar as espécies de Olpidiopsis em gêneros diferentes sem um estudo filogenético do táxon; e de acordo com Klochkova et al. (2016), que também não adotaram a classificação proposta por Dick (2001a, 2001b) na descrição de novas espécies de Olpidiopsis; e considerando que a remoção de O. karlingae para Cornumyces não contribui para esclarecimento do seu posicionamento taxonômico; é proposta a manutenção de $O$. karlingae em Olpidiopsis, permanecendo no gênero de acordo com a classificação de Sparrow (1960) 
e, consequentemente, Cornumyces karlingae (J.S. Karling) M.W. Dick seja sinonímia de $O$. karlingae .

\section{Olpidiopsis $\mathrm{sp} 1$}

Fig. 5a-e

Micélio endobiótico, holocárpico, não causando hipertrofia evidente no hospedeiro. Zoosporângio um a vários; hialino; parede lisa; esférico, 5-40 $\mu \mathrm{m}$ diâm., com um tubo de liberação de zoósporos, que se projetam através da superfície da célula do hospedeiro. Zoósporos não observados. Oogônio com oósporo plerótico, podendo ocorrer simultaneamente com zoosporângios. Oósporo partenogenético, esférico, 10-30 $\mu \mathrm{m}$ diâm., excluindo os espinhos, oval, contendo um glóbulo refrativo recoberto por uma camada de protoplasma vacuolar; endosporo $0,5-1 \mu \mathrm{m}$ de espessura; exosporo $1,5-2,5 \mu \mathrm{m}$ de espessura, coberto por espinhos de até $4 \mu \mathrm{m}$ de comprimento. Anterídio ausente. Germinação do oósporo não observada.

Material examinado: BRASIL. BAHIA: Pilão Arcado, 23.IX.2007, E.P. Rodrigues. A.A. Cronemberguer. ZFBR 033.

Distribuição geográfica no Brasil: táxon inespecífico.

Provavelmente, este é o primeiro relato de Olpidiopsis parasitando fungo do filo Glomeromycota. Não foi possível determinar a identidade taxonômica do hospedeiro, mas possivelmente, seja um representante de FMA (fungo micorrízico arbuscular). Olpidiopsis sp1 produziu estruturas vegetativas e reprodutivas apenas nos esporos do fungo endomicorrízico. Oósporos foram encontrados juntos com zoosporângios em um mesmo esporo do hospedeiro (Fig. 5a-b). Comumente foram observados vários zoosporângios, geralmente esféricos, produzidos em um mesmo esporo (Fig. 5b-d). Uma característica marcante deste espécime é a formação de oósporo de parede muito espessa, coberto com fibrilas longas (Fig. 5e). A espécie mais próxima deste isolado, considerando aspectos morfológicos, é Olpidiopsis gracilis (E.J. Butler) Karling. Foi observado em $O$. gracilis endósporo com 0,7-1,2 um de espessura e exosporo com 1,72,5 $\mu \mathrm{m}$ de espessura, por Whiffen (1942), similares com as medidas observadas neste espécime.

Dick (1997) criou o gênero Gracea composto por organismos holocárpicos, endobióticos, endoparasitas obrigatórios de Peronosporomycetidade, com reprodução assexual por zoosporângios e reprodução sexual homotálica; anterídio ausente; oogônio com ou sem fibrilas externas; oósporo plerótico; e transferiu $O$. gracilis para este novo gênero. Reunindo parte de características dos gêneros Olpidiopsis M. Cornu [pro parte tipo excluso] e de Pseudolpidium A. Fisch [pro parte tipo excluso], Dick (1997) erigiu o gênero Gracea M.W. Dick e, segundo este esquema taxonômico, Gracea tem posição incertae sedis e é intermediário entre Olpidiopsidales e Rozellopsidales, constituído por duas espécies: Gracea waterhouseae (Karling) M.W. Dick, originada com a combinação de Rozellopsis waterhouse Karling e Gracea gracilis (E.J. Butler) M.W. Dick, que anteriormente já havia sido transferida por Karling (1942) de Pseudolpidium gracile E.J. Butler para Olpidiopsis gracilis (E.J. Butler) Karling. A transferência de O. gracilis para Gracea, um gênero de posição incertae sedis, não contribuiu para um melhor posicionamento taxonômico da espécie em relação ao que anteriormente se encontrava.

Apesar do isolado deste estudo o hospedeiro ser diferente daqueles de $O$. gracilis ( $=G$. gracilis), apresenta características análogas a $O$. gracilis, tais como, ser holocárpico, endobiótico, endoparasita, com reprodução assexual por zoosporângios e reprodução sexual homotálica; anterídio ausente; oogônio com fibrilas externas e oósporo plerótico. De acordo com os critérios taxonômicos historicamente adotados em Olpidiopsis, a identificação de um novo hospedeiro seria suficiente para descrição de uma nova espécie (Sparrow 1960; Dick 1997, 2001a, 2001b). O critério taxonômico associado ao hospedeiro como caráter diagnóstico para uma determinada espécie é inconsistente. Originalmente, O. gracilis foi observado parasitando Pythium intermedium. Em teste de variedade de hospedeiros, Pemberton et al. (1990) observaram que vinte espécies de Pythium e duas de Phytophthora foram infectadas por $O$. gracilis, ampliando consideravelmente a gama de oomicetos hospedeiros do parasita. Observando que, enquanto não se suprir novas descrições com dados genéticos moleculares além dos dados morfológicos (e ecológicos), o que não foi possível neste estudo, é prudente evitar novas descrições fundamentadas apenas em correlações morfológicas com as espécies já descritas e seus hospedeiros conhecidos, como ressaltado por Sekimoto et al. (2009); Fletcher et al. (2015); Klochkova et al. (2016) e Kwak et al. (2017).

$\mathrm{O}$ relato de parasitismo de Olpidiopsis em fungo do filo Glomeromycota é inusitado e requer complementação de caracterização filogenética molecular do parasita e do hospedeiro, concatenando com as perspectivas dos avanços da taxonomia. 

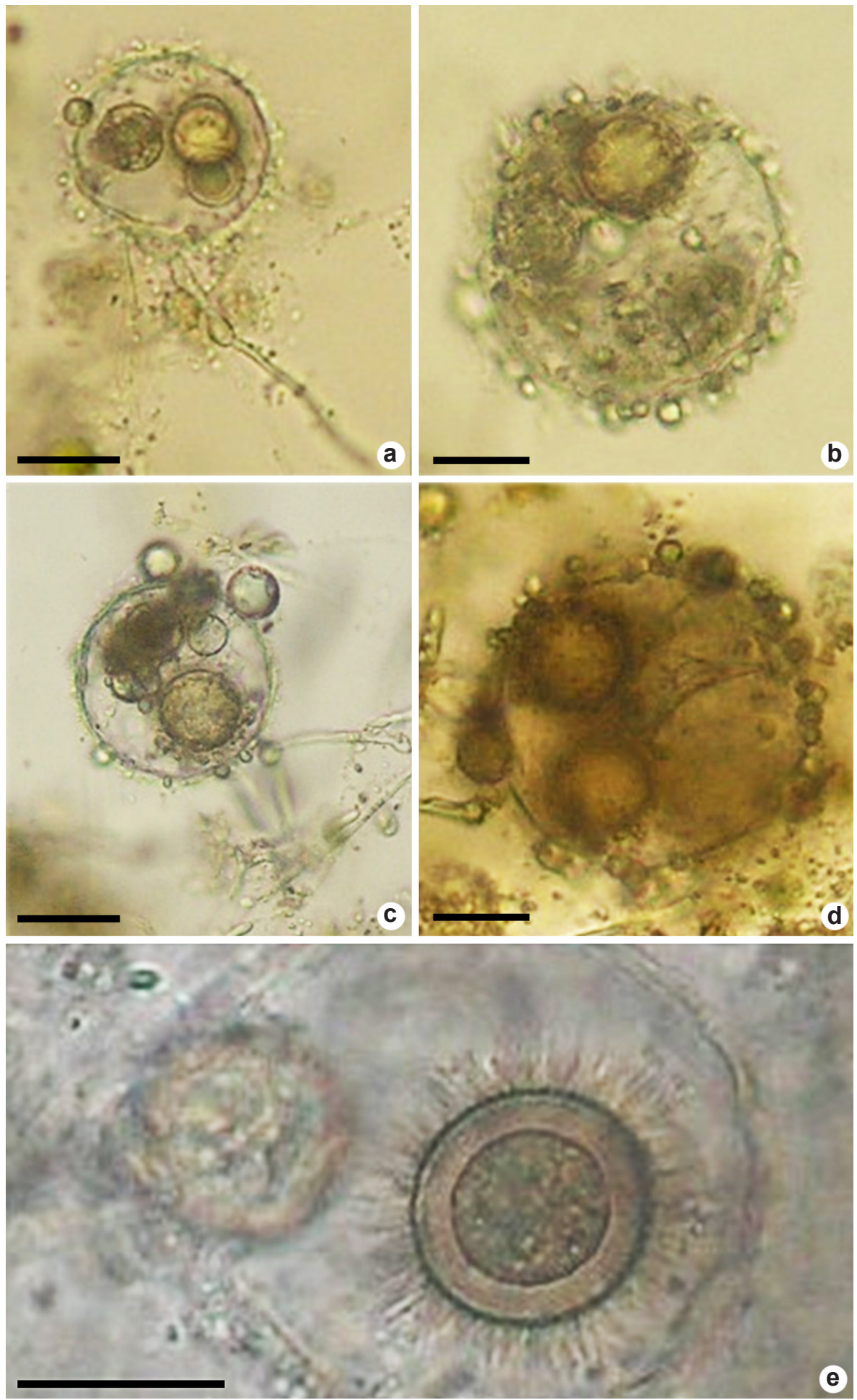

Figura 5 - Estruturas de Olpidiopsis sp1 produzidas em esporos de fungo endomicorrízico (Glomeromycota) - a. esporo com zoosporângios e oósporo; b. esporo com zoosporângios; c. esporo com zoosporângios; d. esporo com zoosporângios; e. esporo com um oósporo de parede muito espessa, coberto com fibrilas longas. Barras $=45 \mu \mathrm{m}$. Figure 5 - Olpidiopsis sp1 structures produced in spores of endomycorrhizal fungi (Glomeromycota) - a. spore with zoosporangium and oospore; b. spore with zoosporangia; c. spore with zoosporangia; d. spore with zoosporangia; e. spore with a very thick wall oospore, covered with long fibrils. Bars $=45 \mu \mathrm{m}$. 
Olpidiopsis sp2.

Fig. 6a-f

Micélio endobiótico, holocárpico, não causando hipertrofia no hospedeiro. Zoosporângio um a vários; geralmente oval, esférico 15-30 $\mu \mathrm{m}$ diâm., elipsoide, variável em tamanho; parede lisa; hialina; um tubo de liberação de zoósporos, cilíndrico, 3-17 $\mu \mathrm{m}$ de comprimento. Zoósporos não observados. Oogônio com oósporo plerótico. Oósporo esférico, 13-30 um diâm., com um ou mais glóbulos refrigentes; parede do exosporo hialina, lisa, espessa, 1,5-3,5 $\mu \mathrm{m}$. Anterídio não observado.

Material examinado: BRASIL. PIAUÍ: Pedro II, Açude Joana, 25.IV.2016, J.L. Machado. ZFBR 168.

Distribuição geográfica no Brasil: táxon inespecífico.

Olpidiopsis sp2 é parasita de esporos de fungo endomicorrízico (Glomeromycota) de espécie não identificada por insuficientes caracteres diagnósticos nas amostras. O parasita tem zoosporângios com um tubo de liberação de zoósporos que atravessa a parede do esporo do hospedeiro (Fig. 6a-b) e pode produzir, simultaneamente, vários zoosporângios globosos e esféricos, apresentando conteúdo granular (Fig. 6cf) O oósporo do parasita apresenta parede espessa, lisa e conteúdo granular (Fig. 6f).

$\mathrm{O}$ isolado estudado não causou dilatação no esporo do hospedeiro, um fungo do filo Glomeromycota (micorriza) não identificado em nível específico. As estruturas morfológicas do parasita são similares a Olpidiopsis indica G.C. Srivast em formas, quantidades e tamanhos, mas, estudos filogenéticos mais específicos são necessários para confirmação precisa da posição taxonômica dos espécimes estudados. $O$. indica apresenta zoosporângios de 17-24 بm diâm., parede lisa, hialina, tubo de liberação cilíndrico; oogônio com oósporo de parede lisa, hialina, 1,7-3,4 um diâm.; um a três anterídios por oogônio. Mas, neste estudo, não foi possível distinguir anterídios de zoosporângios, porque ambas as estruturas podem apresentar tamanhos e formas semelhantes. Para erigir $O$. indica, Srivastava (1975) considerou os critérios de classificação de espécies de Olpidiopsis adotados por Sparrow (1960), a identidade do hospedeiro e a morfologia do oósporo. O hospedeiro original de $O$. indica foi Pythium aphanidermatum (Edson) Fitz. e o oósporo apresenta parede lisa, uma caraterística que ocorre em poucas espécies de Olpidiopsis.

\section{Conclusão}

Historicamente, a identificação do hospedeiro original de Olpidiopsis era priorizada e se refletida na denominação das espécies. $O$ achlyae recebeu este epíteto por ser parasita em Achlya, $O$. saprolegniae em Saprolegnia, O. aphanomycis em Aphanomyces, O. pythii em Pythium, O. karlingae em Karlingia, etc. Este procedimento permanece na denominação de novas espécies. O. porphyrae é parasita em Porphyra (Sekimoto et al. 2008b), $O$. bostrychiae em Bostrychia (Sekimoto et al. 2009), O. pyropiae em Pyropia (Kochkova et al. 2016) etc.

Segundo Flectcher et al. 2015, a classificação das espécies de Olpidiopsis baseada em características morfológicas é considerada muito especulativa. A posição filogenética das espécies de Olpidiopsis através de estudos moleculares deve ser considerada o caminho para expandir o conhecimento deste gênero altamente diverso. Porém, a análise genética tem sido realizada em somente algumas espécies. As poucas espécies terrestres ou de água doce para as quais se tem disponível alguma informação sobre ultraestrutura são O. saprolegnia (Bortinick et al. 1985) e $O$. varians (Martin \& Muller 1986a; 1986b; 1986c), e quatro espécies e uma variedade marinhas, $O$. prophyarae (Sekimoto et al. 2008a), O. bostrychiae (Sekimoto et al. 2009), O. feldmanni (Fletcher et al. 2015), O. pyropiae (Klochkova et al. 2016) e O. porphyrae var. koreanae (Kwak et al. 2017). Todas as seis espécies conhecidas de Olpidiopsis que foram descritas como endoparasitas de algas marinhas vermelhas apresentam morfologia muito simples, são holocárpicas e não oospóricas, nenhum estágio sexual foi relatado para alguma destas espécies de ambiente marinho e a identificação dessas novas espécies requereu estudos filogenéticos moleculares e de microscopia de transmissão visando garantir a identidade das mesmas (Sekimoto et al. 2009; Fletcher et al. 2015; Klochkova et al. 2016; Kwak et al. 2017).

Em contrapartida, segundo Dick (1997), a filogenia é a estimação de passos e a sequência desses passos conduz para a biodiversidade. A filogenia é determinada por probalibidade estatística, baseada em informações disponíveis e adequadas para análise. A filogenia não está sujeita a provas científicas. A concordância entre diferentes e independentes critérios pode fornecer probabilidades muito fortes de afinidade e sequência de passos evolucionários, mas, 

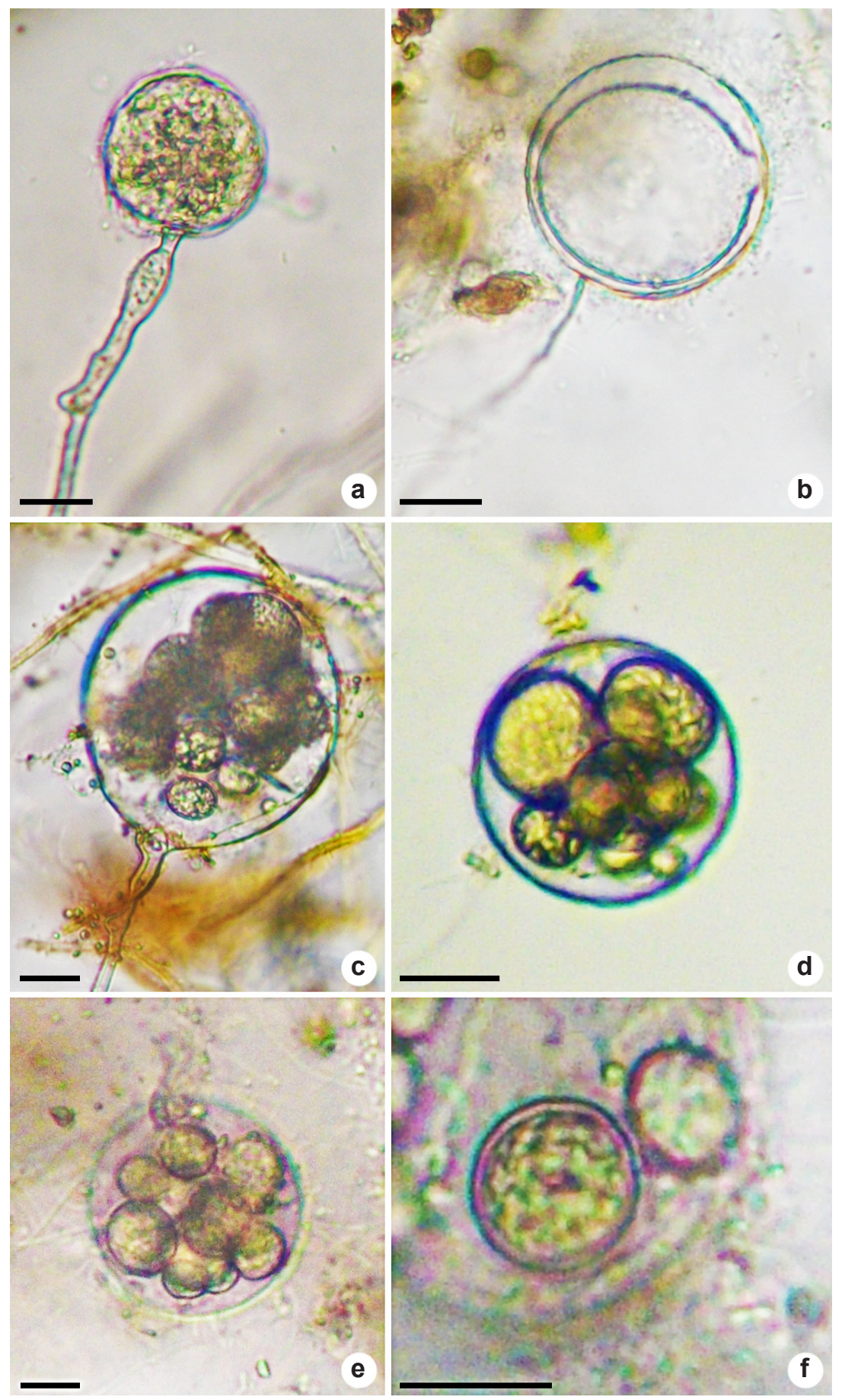

Figura 6 - Estruturas de Olpidiopsis sp2 produzidas em esporos de fungo micorrízico (Glomeromycota) - a. aspecto geral de fungo micorrízico hospedeiro; b. zoosporângio com tubo de liberação atravessado a parede do esporo do hospedeiro, vazio, após a liberação de zoósporos; c. esporo do hospedeiro com zoosporângios; d. esporo com zoosporângios globosos e esféricos, conteúdo granular; e. esporo com vários zoosporângios globosos e esféricos; f. oósporo de parede espessa, lisa, e conteúdo granular. Barras $=45 \mu \mathrm{m}$.

Figure 6 - Olpidiopsis sp2 structures produced in mycorrhizal fungal spores (Glomeromycota) - a. general appearance of host mycorrhizal fungi; b. zoosporangium with release tube traversed the empty spore wall of the host after the release of zoospores; $\mathrm{c}$. host spore with zoosporangia; $d$. spore with globular and spherical zoosporangia, granular content; e. spore with several globular and spherical zoosporangia; f. oospore with thick and smooth wall, and granular content. Bars $=45 \mu \mathrm{m}$. 
permanecem como probabilidades. Ainda segundo Dick (1997), os dados moleculares não podem ser o único árbitro dos grupamentos filogenéticos e da hierarquia, os quais devem ser baseados em diversos e independentes critérios.

Geralmente, é rara a disponibilidade de referências de sequências moleculares de parasitas zoospóricos heterotróficos, especialmente os endobióticos holocárpicos. Uma razão é que vários desses parasitas são biotróficos, os quais não podem se desenvolver sem os seus hospedeiros (Gleason et al. 2014), porisso são de difícil cultivo. O uso do método de iscagem com substratos orgânicos permite obter cultura de hospedeiro-parasita, e possibilita a identificação desses organismos usando características morfológicas (e ecológicas) e permite a observação direta da interação hospedeiro-parasita. O entendimento da dinâmica do desenvolvimento da relação hospedeiro-parasita pode ser essencial na análise dessas interações (Sime-Ngando 2012; Gleason et al. 2014).

\section{Agradecimentos}

À Coordenação de Aperfeiçoamento de Pessoal de Nível Superior (CAPES), a concessão de bolsa à Joseane Lustosa Machado e Janete Barros da Silva. Ao Programa Institucional de Bolsa de Iniciação Científica PIBIC/CNPq-UFPI, a conssessão de bolsa a Edilson Páscoa Rodrigues (2009-2010) e Leilane de Abreu Santos (20112012). Ao Programa de Pesquisa em Biodiversidade do Semi-Árido PPBIO, a bolsa ITI-A, concedida à Áurea Aguiar Cronemberger (2007-2008). Ao Dr. Bruno Tomio Goto, da Universidade Federal do Rio Grande do Norte, por auxiliar no estudo com micorrizas. Aos estagiários do Laboratório de Fungos Zoospóricos da Universidade Federal do Piauí, pelo auxílio na manutenção das culturas.

\section{Referências}

Barrett JT (1912) Development and sexuality of some species of Olpidiopsis (Cornu) Fischer. Annals of Botany 26: 209-238.

Beakes GW, Honda D \& Thines M (2014) Systematics of the Straminipila: Labyrinthulomycota, Hyphochytridiomycota, and Oomycota. In: McLaughlin DJ and Spatafora JW (eds.) Systematics and evolution. The Mycota. VIII Part A. $2^{\text {nd }}$ ed. Springer-Verlag, Berlin, Heidelberg. Pp. 39-97.

Bortnick RN, Powell MJ \& Bangert TN (1985) Zoospore fine structure of the parasite Olpidiopsis saprolegniae variety saprolegniae (Oomycetes, Lagenidiales). Mycologia 77: 861-879.
Butler EJ \& Bisby GR (1931) The fugi of India. Mono 1, XVIII. Council of Agricultural Research, Calcutta, $237 \mathrm{p}$.

Cornu MM (1872) Monographie des Saprolégniées. Étude physiologique et systématique. Annales des Sciences Naturelles, Botanique, Série 5, 15: 5-198.

Dangeard PA (1890) Contribution à l'étude des organismes inférieurs. Le Botaniste 2:1-58.

Dick MW (1997) The Myzocytiopsidaceae. Mycological Research 101: 878-882

Dick MW (2001a) The Peronosporomycetes. In: McLaughlin DJ, McLaughlin EG, Lemke PA(eds.) The Mycota VII. Part A. Systematics and evolution. Springer Vrelag, Berlin. Pp. 39-72.

Dick MW (2001b) Straminipilous fungi: systematics of the Peronosporomycetes including accounts of the marine Straminipilous Protists, the Plasmodiophorids and similar organisms. Kluwer Academic Publisher. Dordrecht. 670p.

Fletcher K, Žuljevi'c A, Tsirigoti A, Antoli'c B, Katsaros C, Nikoli'c V, van West P \& Küpper FC (2015) New record and phylogenetic affinities of the oomycete Olpidiopsis feldmanni infecting Asparagopsis sp. (Rhodophyta). Diseases of Aquatic Organisms 117: 45-57.

Forzza RC, Stehmann JR, Nadruz M, Costa A, Carvalho Jr. AA, Walter BMT, Bicudo C, Moura CWN, Zappi D, Peralta DF, Costa DP, Barros F, Martinelli G, Lima HC, Prado J, Baumgratz JFA, Pirani JR, Sylvestre LS, Maia LC, Lucia G, Lohmann LG, Paganucci L, Alves MVS, Mamede MCH, Soares ML, Morim MP, Barbosa MR, Menezes M, Evangelista PHL, Viana PL, Goldenberg R, Secco R, Rodrigues RRS, Cavalcanti T, Mansano V \& Souza VC (orgs.) (2010) Catálogo de plantas e fungos do Brasil. Vol. 1. Andrea Jakobsson Estudio, Jardim Botânico do Rio de Janeiro, Rio de Janeiro. 871p.

Fuller MS \& Jaworski A (1987) Zoosporic fungi in teaching and research. Southeastern Publishing Corporation, Athens. 303p.

Gleason FH, Lilje O, Marano AV, Sime-Ngando T, Sullivan BK, Kirchmair M \& Neuhauser S (2014) Ecological functions of zoosporic hyperparasites. Frontiers in Microbiology. Aquatic Microbiology 5: $1-10$.

Hudson PJ, Dobson AP \& Lafferty KD (2006) Is a healthy ecosystem one that is rich in parasites? Trends in Ecololgy \& Evolution. 21: 381-385

Johnson Jr. TW, Seymour RL \& Padgett DE (2002) Biology and the systematics of the Saprolegniaceae. Ilumina. Disponível em $<$ http://dl.uncw.edu/digilib/ biology/fungi/taxonomy $\% 20$ and $\% 20$ systematics/ padgett $\% 20$ book> . Acesso em 24 janeiro 2017.

Karling JS (1942) The simple holocarpic biflagellate Phycomycetes, including a complete Host Index and Bibliography. New York. 148p. 
Karling JS (1944) Brazilian anisochytrids. American Journalof Botany 31: 391-397.

Karling JS (1949) A new Olpidiopsis parasite of Karlingia rosea from Maryland. Mycologia 41: 270-276.

Karling JS (1960) Parasitism Among the Chytrids. II Chytriomyces verrucosus sp. nov. and Phlyctochytrium synchytrii. Bulletin of the Torrey Botanical Club 87: 326-336.

Kim GH, Moon K-H, Kim J-Y, Shim J \& Klochkova TA (2014) A revaluation of algal diseases in Korean Pyropia (Porphyra) sea farms and their economic impact. Algae 29: 249-265.

Kirk PM, Cannon PF, Minter DW \& Stalpers JA (2008) Dictionary of fungi. $10^{\text {th }}$ ed. CABI Publishing, Wallingford. 784p.

Klochkova TA, Yoon JS, Moon K-H, Motomura T \& Kim GH (2016) New species of unicellular obligate parasite, Olpidiopsis pyropiae sp. nov., that plagues Pyropia sea farms in Korea. Journal of Applied Phycology 28: 73-83.

Khulbe RD (1979) Occurrence of parasitic watermolds in some laks of Nainital, India. Hydrobiologia 70: 119-121.

Kwak MS, Klochkova TA, Jeong S \& Kim GH (2017) Olpidiopsis porphyrae var. koreanae, an endemic endoparasite infecting cultived Pyropia yezoensis in Korea. Journal of Applied Phycology. Doi 10.1007/s10811-017-1109-3. Acesso em 24 janeiro 2017.

Kuris AM, Hechinger RF, Shaw JC, Whitney KL, Aguirre-Macedo L \& Boch CA (2008) Ecosystem energetic implications of parasites and free-living biomass in three estuaries. Nature 7203: 515-518.

Lafferty KD, Dobson AP \& Kuris AM (2006) Parasite dominate food web links. Proceedings of the National Academy of Sciences of the United States of America 103: 11211-11216.

Lafferty KD, Allesina S, Arim M, Briggs CJ, Leo G \& Dobson AP (2008) Parasite in food webs: the ultimate missing links. Ecology Letters 11: 533-546.

Maia LC, Carvalho AA, Cavalcanti LH, Gugliotta AM, Drechsler-Santos ER, Santiago ALMA, Cáceres MES, Gibertoni TB, Aptroot A, Giachini AJ, Soares AMS, Silva ACG, Magnago AC, Goto BT, Lira CRS, Montoya CAS, Pires-Zottarelli CLA, Silva DKA, Soares DJS, Rezende DHC, Luz EDMN, Gumboski EL, Wartchow F, Karstedt F, Freire FM, Coutinho FP, Melo GSN, Sotão HMP, Baseia IG, Pereira J, Oliveira JJS, Souza JF, Bezerra JL, Araujo Neta LS, Pfenning LH, Gusmão LFP, Neves MA, Capelari M, Jaeger MCW, Pulgarín MP, Menolli Junior N, Medeiros PS, Friedrich RCS, Chikowski RS, Pires RM, Melo RF, Silveira RMB, UrreaValencia S, Cortez VG \& Silva VF (2015) Diversity of Brazilian fungi. Rodriguésia 66: 1033-1045.
Marano AV, Gleason FH, Baerlocher F, Pires-Zottarelli CLA, Lilje O \& Schmidt SK (2012) Quantitative methods for the analysis of zoosporic fungi. Journal of Microbiological Methods 89: 22-32.

Martin RW \& Miller CE (1986a) Ultrastructure of mitosis in the endoparasite Olpidiopsis varians. Mycologia 78: 11-21.

Martin RW \& Miller CE (1986b) Ultrastructure of sexual reproduction in Olpidiopsis varians. Mycologia 78: 359-370.

Martin RW \& Miller CE (1986c) Ultrastructure of zoosporogenesis in the endoparasite Olpidiopsis varians. Mycologia 78: 230-241.

McLarty DA (1941) Studies in the family Woroninaceae. II. The citology of Olpidiopsis achlyae sp. nov. (ad. int.) Bullein of the Torrey Botanical Club 68: 75-99.

Milanez AI, Pires-Zottarelli CLA \& Schoenlein-Crusius IH (1995) Criptógamos do "Parque Estadual das Fontes do Ipiranga", São Paulo, SP. Fungos, 2: Lagenidiales. Hoehnea 22: 115-123.

Milanez AI (1989) Fungos de águas continentais. In: Fidalgo O \& Bononi VL (coords.) Técnicas de coleta, preservação e herborização de material botânico. Série Documentos. Instituto de Botânica, São Paulo. Pp. 17-20.

Milanez AI, Pires-Zottarelli CLA \& Gomes AL (2007) Brazilian zoosporic Fungi. Conselho Nacional de Pesquisa, São Paulo. 117p.

Pemberton CM, Davey RA, Webster J, Dick MW \& Clark G (1990) Infection of Pythiurn and Phytophthova species by Olpidiopsis gracilis (Oomycetes). Mycological Research 94: 1081-1085.

Pires-Zottarelli CLA (1999) Fungos zoospóricos dos vales dos rios Moji e Pilões, região de Cubatão, SP. Tese de Doutorado. UNESP, Rio Claro. 300p.

Rocha JRS (2002) Fungos zoospóricos em áreas de cerrado no "Parque Nacional de Sete Cidades", Piauí, Brasil. Tese de Doutorado. USP, São Paulo. 266p.

Rogers AL, Milanez AI \& Beneke ES (1970) Additional aquatic fungi from the São Paulo state. Rickia 5: 93-110.

Sekimoto S, Beakes GW, Gachon CMM, Muller DG, Kupper FC \& Honda D (2008a) The development, ultrastructural cytology, and molecular phylogeny of the basal oomycete Eurychasma dicksonii, infecting the filamentous phaeophte algae, Ectocarpus siliculosus and Pylaiella littoralis. Protist 159: 299-318.

Sekimoto S, Yokoo K, Kawamura Y \& Honda D (2008b) Taxonomy, molecular phylogeny, and ultrastructural morphology of Olpidiopsis porphyrae sp. nov. (Oomycetes, straminipiles), a unicelular obligate endoparasite of Porphyra spp. (Bangiales, Rhodophyta). Mycological Research 112: 361-374.

Sekimoto S, Klochkova TA, West JA, Beakes GW \& Honda D (2009) Olpidiopsis bostrychiae sp. nov.: 
na endoparasitic oomycete that infects Bostrychia and other red algae (Rhodophyta). Phycologia 48: 460-472.

Shanor L (1939) Studies in the genus Olpidiopsis. I. Restings pore germinationi n a new species. Journal of the Elisha Mitchell Science Society 55: 167-177.

Shanor L (1940) Studies in the genus Olpidiopsis. III. Some observations on the host range of certain species. Journal of the Elisha Mitchell Science Society 55: 165-176.

Shearer CA, Descals E, Kohlmeyer B, Kohlmeyer J, Marvanova L, Padgett D, Porter D, Raja HA, Schmit JP, Thorton HA \&Voglymayr H (2007) Fungal biodiversity in aquatic habitats. Biodiversity Conservation 16: 49-67.

Sime-Ngando T (2012) Phytoplankton chytridiomycosis: fungal parasites of phytoplankton and their imprints on the food web dynamics. Frontiers in Microbiology. Aquatic Microbiology 3: 1-13.

Slifkin MK (1961) Parasitismo of Olpidiopsis incrassata on members of the Saprolegniaceae. I. Host range and effects of light, temperature and stage of host on infectivity. Mycologia 53: 183-193.
Sparrow J (1960) Aquatic phycomycetes. $2^{\text {nd }}$ ed. University of Michigan Press, Ann Arbor. 1187p.

Species fungorum (2017) Species fungorum. Centre for Agriculture and Bioscience Internationla. CABI database. Disponível em <http://www. speciesfungorum.org $>$. Acesso em 16 janeiro 2017.

Srivastava GC (1975) Olpidiopsis indica sp. nov. from India. Current Science, Letters to the Editor 44: 642-644.

Staniak J (1971) Investigations on aquatic fungi in Lubelskie Province. Annales Universitatis Mariae Curie-Skłodowska, Ser. C 26: 353-379.

Steciow MM, Milanez AI, Pires-Zottarelli CLA, Marano AV, Lecther PM \& Vélez CG (2012) Zoosporic true fungi, heterotrophic straminipiles and plasmodiophorids status of knowledge in South America. Darwiniana 5: 25-32.

Upadhyay M \& Palni UT (2009) Occurrence of parasitic watermolds in selected forest soils of Nainital, Indian Central Himalaya. Nature and Science 7: 45-48.

Whiffen AJ (1942) Two new chytrid genera. Mycologia 34: 543-557. 